\title{
Os interesses políticos no processo de criação da Região Metropolitana de Umuarama, PR
}

\author{
Political interests in the creation process \\ of the Metropolitan Region of Umuarama, State of Paraná
}

Renato Alves de Oliveira [I]

William Antonio Borges [II]

\begin{abstract}
Resumo
Neste trabalho, buscou-se construir uma inteligibilidade sobre os interesses políticos inscritos no processo de criação da Região Metropolitana de Umuarama (RMU). Para tanto, a pesquisa mobilizou a legislação vigente, o Estatuto da Metrópole, base jurídica para a dinâmica metropolitana e que estabelece critérios para a instituição de novas RMs. 0 percurso teórico abordou a literatura referente à questão metropolitana no Brasil e sobre 0 processo de políticas públicas. A metodologia empregada envolveu pesquisa documental e pesquisa de campo realizadas por meio de entrevistas semiestruturadas. Como resultado, a narrativa construída conta-nos que a decisão de criação da RMU foi baseada em interesses políticos, vinculados ao status de pertencer a uma RM, interesses imobiliários e eleitoreiros.
\end{abstract}

Palavras-chave: Região Metropolitana de Umuarama; governança interfederativa; Estatuto da Metrópole, interesses políticos.

\begin{abstract}
In this article, we sought to understand the political interests inscribed in the process of creating the Metropolitan Region of Umuarama $(M R U)$. For that, the research mobilized the current legislation, the Metropolis Statute, which is the legal basis for the metropolitan dynamics and establishes criteria for the institution of new MRs. The theoretical approach covered the literature on the metropolitan issue in Brazil and on the public policy process. The methodology involved documentary research and field research carried out through semi-structured interviews. As a result, the constructed narrative tells us that the decision to create the MRU was based on political interests connected with the status of belonging to a $M R$, on real estate interests and on electoral interests.
\end{abstract}

Keywords: Metropolitan Region of Umuarama; interfederative governance; Metropolis Statute; political interests. 


\section{Introdução}

A questão metropolitana é, atualmente, um dos maiores desafios da agenda urbana brasileira, além de ser estratégica para que as cidades consigam, de fato, enfrentar seus históricos passivos (Marguti; Costa e Favarão, 2018). Expressivas transformações em escala mundial, desde a década de 1970, trouxeram mudanças notáveis, tanto na escala da rede urbana como na do espaço urbano (Sposito, 2001). Segundo o IBGE (2010), a taxa de urbanização brasileira é cerca de $84,4 \%$ da população, e grande parte dessa população reside em Regiões Metropolitanas (RMs).

Uma Região Metropolitana (RM) é composta por uma metrópole ou capital regional e um agrupamento de municípios limítrofes que integrem planejamento, organização e execução de Funções Públicas de Interesse Comum (FPICS). As RMs representam um fator de desenvolvimento, pois a maior cidade tem papel fundamental no processo de integração e desenvolvimento das demais que compõem a Aglomeração Metropolitana (Bernardes et al., 1971). Além disso, no contexto metropolitano, os municípios que anseiam fazer parte de uma RM têm a expectativa de acesso a recursos federais voltados às RMs ou de obtenção de benefícios, tais como integração de transporte público, por exemplo (Borges, 2013).

Com a promulgação da lei federal $n$. 13.089, de 2015, o Estatuto da Metrópole estabelece as diretrizes que orientam a integração e a articulação de políticas públicas em RMs, Aglomerações Urbanas (AUs) e Microrregiões (Moura e Hoshino, 2015) e prevê a governança metropolitana e a FPIC. Para caracterizar uma RM, o Estatuto da Metrópole criou critérios para medição da influência da cidade-polo e estabeleceu que sejam utilizados os estudos desenvolvidos e disponibilizados pelo IBGE. No entanto, interesses políticos têm desconsiderado algumas das diretrizes do Estatuto da Metrópole, como as FPICs, resultando na criação arbitrária de muitas RMs (Moura e Hoshino, 2015; Moraes; Guarda e Zacchi, 2018).

Das 74 RMs formalmente constituídas no Brasil (IBGE, 2018), 8 estão no estado do Paraná. Entre essas RMs, encontra-se a Região Metropolitana de Umuarama (RMU), com população estimada em 313.794 habitantes (Ipardes, 2019). Segundo dados que constam da publicação Arranjos populacionais e concentrações urbanas no Brasil (IBGE, 2016), bem como do estudo denominado "Política de desenvolvimento urbano e regional para o estado do Paraná" (PDUR, 2017), o município de Umuarama não se qualifica como capital regional de Nível B, e a sua RM não apresenta elementos mínimos que constatem a interdependência entre os municípios, o que, de acordo como Estatuto da Metrópole, denota ausência de legitimidade para se manter como RM. E, visto que os já mencionados interesses políticos têm desconsiderado algumas das diretrizes do Estatuto da Metrópole, o objetivo do presente trabalho é construir uma inteligibilidade sobre os interesses políticos inscritos no processo de criação e de implementação da RMU em diálogo com o Estatuto da Metrópole.

Este artigo está estruturado em cinco seções, a começar com a introdução. Na sequência, na segunda seção, têm-se a mobilização e composição dos aspectos teóricos que fundamentaram o presente trabalho, ou seja, uma leitura sobre a questão metropolitana no Brasil, o Estatuto da Metrópole, a caracterização de uma RM, a criação arbitrária de RMs no Brasil, a prevalência de critérios políticos nesse 
âmbito e o processo do ciclo de Políticas Públicas. Este último com o intuito de amparar teoricamente a dinâmica de criação e implementação de um RM. Na terceira seção, são apresentados os procedimentos metodológicos empregados para o desenvolvimento da pesquisa, destacando os registros mobilizados e produzidos em campo, bem como seu tratamento. A quarta seção compreende a construção de uma inteligibilidade sobre os interesses políticos inscritos no processo de criação e implementação da RMU. E, finalizando o trabaIho, encontram-se as considerações finais.

\section{A questão metropolitana no Brasil}

A questão metropolitana no Brasil surge na década de 1950, no contexto do processo de intensificação da industrialização e urbanização do País. Na década de 1970, ocorre uma inversão no que se refere ao uso e à ocupação do território nacional, momento em que a população brasileira passou a se concentrar em maioria nos centros urbanos, principalmente nas metrópoles que se constituíam (Barbosa, 2010). No entanto, as cidades não estavam preparadas para uma grande leva de migrantes (Tavares, 2004). Muitas ultrapassaram seus limites político-administrativos e "foram se incorporando às cidades-polo, integrando o que se convencionou chamar de área metropolitana", resultando em grandes centros urbanos e em vários problemas característicos, como "insuficiência da rede de equipamentos básicos e de habitações, deficiências no sistema de transporte, dificuldades de circulação, etc." (Carrera-Freitas, 2017, p. 81).
Os primeiros debates sobre a questão metropolitana surgiram na década de 1960, durante o governo militar, na Constituição Federal (CF) de 1967 e na Emenda Constitucional de 1969. Naquele momento, cabia apenas à União a responsabilidade de estabelecer RMs. As primeiras oito RMs foram instituídas em 1973 pela lei federal complementar n. 14, quais sejam: as RMs de São Paulo, Belo Horizonte, Porto Alegre, Recife, Salvador, Curitiba, Belém e Fortaleza (Azevedo e Mares Guia, 2000). No ano seguinte, em 1974, a Região Metropolitana do Rio de Janeiro é criada pela lei complementar n. 20. Esse primeiro momento é marcado por um modelo autoritário e centralista, com a gestão metropolitana baseada nos estados, mas com forte controle do governo federal (Observatório das Metrópoles, 2008).

A lei complementar n. 14 , de 8 de junho de 1973, concedeu aos estados a gestão das regiões metropolitanas (Fernandes Junior, 2004). Porém, foi com a Constituição Federal (CF) de 1988, art. 25, § 3ㅇ, que a competência para instituir as RMs se estabelece nos estados (Carrera-Freitas, 2017).

No que tange ao plano de política urbana metropolitana, a CF de 1988, art. 18, altera o status dos municípios para entidade federada e muda o papel deles para o de protagonista na execução da política urbana, conforme art. 182, com o objetivo de "ordenar o pleno desenvolvimento das funções sociais da cidade e de garantir o bem-estar de seus habitantes" (Brasil, Constituição Federal, 1988).

A CF de 1988 impõe, também, que a construção das políticas públicas urbanísticas deva ocorrer com a participação de todos os entes federados (Souza, 2003). Sendo assim, ainda era necessária a criação de uma 
legislação que fizesse uma ordenação e regulamentasse o convívio entre os entes federados, uma gestão metropolitana a partir de políticas, como instrumento de base jurídica para toda a dinâmica metropolitana.

\section{O Estatuto da Metrópole}

As RMs podem representar um locus de desenvolvimento, no qual a(s) cidade(s)-polo desempenha(m) papel importante no processo de integração regional e a possiblidade concreta para avançar na proposta de gestão pública democrática (Klink, 2009; Bernardes et al. 1971). Para alguns estudiosos, os principais problemas da gestão metropolitana decorriam do fato da inexistência de uma ordem jurídico-institucional bem delineada sobre as RMs, AUs e microrregiões (Santos, 2018; CNPq, 2009, p. 526; Grau, 1974, p. 26; Fernandes Junior, 2003; Balbim et al., 2012).

Uma das primeiras legislações e que sinalizava a necessidade de se planejar as RMs, foi a lei federal n. 10.257 (Brasil, 2001), o Estatuto da Cidade. Segundo esse Estatuto, todos os municípios com mais de vinte mil habitantes, que integrassem uma RM ou que se constituíssem como localidade turística, precisariam elaborar um Plano Diretor (Borges, 2013), que, nos termos do art. $40, \S 1^{\circ}$, do Estatuto da Cidade, é o instrumento básico da política de planejamento urbano (Carvalho, 2001).

Somente em 12 de janeiro de 2015 foi promulgada a lei federal n. 13.089, denominada Estatuto da Metrópole. A sanção dessa lei trouxe conteúdo normativo, diretrizes gerais para as RMs e AUs, servindo como principal instrumento de base jurídica (Santos, 2018), como a governança interfederativa. Muito embora a CF de 1988 já tratasse de vários princípios para nortear uma RM, a governança interfederativa só foi mencionada no Estatuto da Cidade e posteriormente reafirmada no Estatuto da Metrópole (Carrera-Freitas, 2017).

A governança interfederativa ocorre por meio de pacto territorial firmado entre municípios e estado, a fim de conduzir planos urbano-regionais e políticas de diferentes setores, envolvendo os três entes federativos, com o propósito de encontrar e implementar soluções de problemas comuns dos municípios que integram uma RM (Borges, 2013).

O Estatuto da Metrópole também determina normas gerais para a elaboração de um Plano de Desenvolvimento Urbano Integrado (PDUI). O PDUI, segundo o art. 2º, inciso VI, é um "instrumento que estabelece, com base em processo permanente de planejamento, viabilização econômico-financeira e gestão, as diretrizes para o desenvolvimento territorial estratégico e os projetos estruturantes da região metropolitana e aglomeração urbana" (Brasil, 2015). O PDUI deve ser instituído por lei estadual, orientar o desenvolvimento urbano-regional e estabelecer as bases de atuação conjunta entre estados e municípios (Carrera-Freitas, 2017).

O desafio, com o PDUI, é alcançar o maior grau de solidez possível nos arranjos destinados à governança interfederativa. 0 prazo inicial para que os PDUls estivessem prontos era janeiro de 2018. No entanto, isso não ocorreu (Moraes, Guarda e Zacchi, 2018). Esse prazo foi estendido até o final de 2021, pela medida provisória n. 818, de 11 de janeiro de 2018, que também aprovou o fim da responsabilização por improbidade administrativa dos governadores que deixem de aprovar os PDUIs. 
A esse respeito, é pertinente destacar que, além de o governador de cada estado não incorrer mais em improbidade administrativa, caso seu governo não elabore os PDUls, já não havia previsão de fundos para o financiamento das políticas metropolitanas, o que dissipava de modo significativo a força do Estatuto da Metrópole em um contexto de lacuna institucional (ausência de gestão e de governança metropolitanas, ou seja, de coordenação interfederativa) para lidar com a questão metropolitana no Brasil, o que tem contribuído para o esvaziamento do significado de região metropolitana.

\section{Caracterização de uma região metropolitana}

Para compreender o que caracteriza uma RM, é necessário entender o que é uma metrópole. Para Ascher (1995), uma metrópole é uma aglomeração urbana (AU), com centenas de milhares de habitantes, que mantém relações econômicas com outras AUs. Bernardes et al. (1971, p. 121) destacam outras características, como grande concentração de pessoas, alta complexidade, fluxo intenso de pessoas, equipamentos na quantidade e qualidade proporcionais de um centro nacional ou regional.

Algo que também caracteriza uma metrópole, segundo o IBGE (2008), é o seu porte. Para o referido Instituto, esses núcleos urbanos têm mais de um milhão de habitantes, com forte relação socioeconômica entre os municípios que a compõem e que exercem importante papel econômico, na gestão territorial regional ou nacional. A conurbação também é um processo comum nas metrópoles, resultado do encontro dos núcleos urbanos que cresceram até se tocarem, fundirem-se em uma única mancha urbana, mesmo que mantidos os limites estabelecidos politicamente (Souza, 2003). Além da proximidade, é necessário que os municípios constituam vínculos de caráter social e econômico, resultado das interações espaciais entre os municípios (Santos e Peixinho, 2015). Porém, essa conurbação não é obrigatória. Existem metrópoles que, embora não conurbadas, exercem influência econômica sobre outros municípios, como, por exemplo, Manaus (Borges, 2013).

A partir da compreensão do que é metrópole, é necessário conceituar uma RM e caracterizá-la. Para Grau (1975), além de intensa urbanização e marcante densidade demográfica, a RM precisa ser polo e comunidade de atividades socioeconômicas e ter uma estrutura própria que facilite fluxo peculiares.

Em 1969, na I Conferência Nacional de Geografia e Cartografia, foi defendido que a área metropolitana no Brasil deveria obedecer a três critérios: população, atividade e integração. $O$ grau de integração entre os municípios deve ser medido, segundo o IBGE, por meio da análise dos movimentos pendulares. $O$ último estudo sobre Arranjos Populacionais e Concentrações Urbanas no Brasil (APCUB), publicado em 2016, pelo IBGE, traz a análise dos movimentos pendulares em todas as aglomerações urbanas no Brasil. Quanto mais intensos os movimentos pendulares entre os municípios, maiores são as possibilidades de existência de níveis elevados de interdependência entre os municípios (Carrera-Freitas, 2017).

Mas a principal base legal para a caracterização de uma RM é o Estatuto da Metrópole, que exige que novas RMs só podem ser instituídas se observados os critérios definidos e disponibilizados pelo IBGE, entre estes os movimentos pendulares, assim como 
também que a metrópole deve ter influência nacional ou sobre uma região e que se configure, no mínimo, como uma capital regional nível $\mathrm{B}$, conforme dispõe o parágrafo único do art. $2^{\circ}$ da lei n. 13.089, de 2015.

Outro princípio básico que caracteriza uma RM é a Função Pública de Interesse Comum (FPIC), a essência ou justificativa para a institucionalização dessas unidades territoriais (Santos, 2018). Segundo o art. 2ㅇ, II, FPIC é a existência concreta de política pública ou a ação nela inserida, cuja realização por parte de um município de forma isolada seja inviável ou cause impacto em municípios limítrofes. Com as FPICs, o Estatuto da Metrópole pretende operacionalizar o dever de cooperação entre os entes federativos diante da gestão de problemas comuns (ibid.). Segundo o Estatuto, as leis complementares estaduais que instituírem RMs e AUs deverão prever os municípios integrantes e as FPICs, a estrutura de governança interfederativa, os meios de controle social da organização, do planejamento e a execução das FPICs (ibid.).

Apesar do que foi apresentado até aqui, das exigências e justificativas para a instituição de RMs, observa-se que a criação de RMs, desde a CF de 1988, tem ocorrido de forma arbitrária, conforme a próxima subseção.

\section{A criação arbitrária de regiões metropolitanas no Brasil: prevalência de critérios políticos}

Embora o Estatuto da Metrópole estabeleça uma caracterização para as RMs, apresentando critérios mínimos para a sua constituição, estudiosos defendem que essas exigências poderiam ser ainda mais restritivas (Moura e Hoshino, 2015), pois, de acordo com estudos realizados, utilizando-se de critérios do IBGE, de cortes populacionais de médias e grandes concentrações urbanas, foram identificadas 26 grandes concentrações urbanas com mais de 750.000 habitantes, sendo apenas 12 legitimadas como metrópoles, número diferente das 74 RMs existentes atualmente (Moraes, Guarda e Zacchi, 2018). É pertinente destacar que o IBGE, por meio da atualização do Regic (Regiões de Influência das Cidades) em 2020, legitima a existência de 15 metrópoles no Brasil, quais sejam: Manaus, Belém, Fortaleza, Recife, Salvador, Brasília, Goiânia, Belo Horizonte, Vitória, Rio de Janeiro, São Paulo, Campinas, Curitiba, Florianópolis e Porto Alegre.

Para Moura e Firkowski (2001, p. 107), o "desejo do status" é o que parece prevalecer, e que "mais que criar regiões, se instituem metrópoles, associadas ao peso simbólico que as relaciona ao progresso e à modernidade". Esse movimento de "Fetiche Metropolitano" reflete um pensamento que ser ou pertencer a uma RM “proporciona benefícios, em geral verbas públicas" (Machado et al., 2016, p. 37). Muitos municípios anseiam fazer parte de uma RM, na expectativa de acesso a recursos federais por meio do Ministério das Cidades, voltados às RMs, e para obterem benefícios, como integração de transporte público, maior representatividade política na luta por incrementos orçamentários junto à União e a integração do sistema de telefonia (Borges, 2013). Nos últimos anos, uma das poucas políticas públicas que têm dado um tratamento diferenciado às RMs é o Programa Minha Casa Minha Vida (PMCMV), por elevar o subsídio e o valor máximo do imóvel aos municípios que integram esses territórios (Cunha, 2014). 
No que tange aos recursos e financiamentos para as RMs, legislações anteriores previam recursos federais e estaduais, como a lei complementar n. 14/1973 e o decreto federal n. 73.600, de fevereiro de 1974 (Santos, 2018, p. 463). Porém, atualmente, no Brasil, não existem aportes de recursos financeiros, em nível federal, para políticas metropolitanas. Mesmo assim, ainda existe uma crença de que podem ser retomadas linhas de financiamentos como as que existiam na década de 1970 (Cunha, 2014; Borges, 2013).

Observando a história recente sobre a criação de regiões metropolitanas pelos estados, após a Constituição de 1988, verifica-se que a maioria não atende aos requisitos técnicos exigidos pela atual legislação (Fernandes e Araújo, 2015) e muito menos expressa dinâmicas territoriais integradas, além de a maior parte de seus municípios não compartilhar Funções Públicas de Interesse Comum, incorrendo apenas em uma fragmentação regional, fragilizando a possibilidade de se constituir governança e gestão metropolitanas efetivas (Santos, 2018).

Para alguns autores, interesses políticos estaduais poderiam explicar o boom na aprovação de novas RMs (ibid.), e a adoção de critérios meramente políticos na decisão de criação de novos arranjos parece prevalecer, o que é prejudicial ao planejamento do território interfederativo (Fernandes, 2004; Moraes, Guarda e Zacchi, 2018).

Para Souza (2003), o conceito anteriormente vigente de RM foi rompido, pois a variável política passou a assumir maior importância, em detrimento da econômica e da físico-espacial, pois ainda vivemos um momento de criação de novas RMs sem critério. 0 estado do Paraná é uma unidade da federação na qual esse fenômeno também ocorre, como será observado na próxima subseção.

\section{Regiões Metropolitanas no Paraná}

Na história recente, o estado do Paraná também tem protagonizado a criação de RMs sem critérios mais precisos e consistentes, conforme delimita o Estatuto da Metrópole. São oito as RMs existentes no estado, envolvendo 194 dos 399 municípios paranaenses (PDUR, 2017): RM de Apucarana, RM de Campo Mourão, RM de Cascavel, RM de Curitiba, RM de Londrina, RM de Maringá, RM de Toledo e a RM de Umuarama. Segundo o PDUR (ibid.), outras oito RMs estão em tramitação na Assembleia Legislativa do Paraná, quais sejam: Cianorte, Cornélio Procópio, Dois Vizinhos, Francisco Beltrão, Foz do Iguaçu, Paranavaí, Pato Branco e União da Vitória.

Das oito RMs formalmente constituídas no estado do Paraná, três destacam-se, as RMs de Curitiba, de Londrina e de Maringá (Cunha, 2014), mas somente a RM de Curitiba deu início à elaboração do PDUI (Fnem, 2018). Segundo a Política de Desenvolvimento Urbano e Regional para o Paraná (PDUR, 2017; 2018), o cenário paranaense não se distingue do restante do País, caracterizado por proliferação generalizada de RMs, inexistência de critérios únicos e inadequação relativa aos novos preceitos estabelecidos pelo Estatuto da Metrópole.

Entre as RMs paranaenses, encontra-se a Região Metropolitana de Umuarama (RMU), objeto do presente estudo. Criada pela lei 
complementar estadual n. 149, de agosto de 2012, possui 24 municípios inscritos (Paraná, 2012) e população de 313.794 habitantes (Ipardes, 2019). A RMU será abordada em uma subseção posterior.

É pertinente destacar que uma RM representa um território intermunicipal integrado, base para estruturar planos e ações para o desenvolvimento territorial, urbano e social (Abrucio, 2010; Bernardes et al., 1971). Nesse sentido, é necessário o desenvolvimento de políticas públicas também integradas, ainda mais quando se trata de um território metropolitano.

Para tanto, é pertinente mobilizar o aporte teórico sobre o ciclo de políticas públicas, principalmente para compreender o processo de formulação e implementação, com o intuito de sustentar a leitura sobre a RMU.

\section{O ciclo de políticas públicas: formulação de política pública no contexto da constituição da agenda e sua implementação}

Antes de abordar o ciclo de políticas públicas, faz-se necessário mobilizar o que se entende como política pública. Para Secchi (2010) e Frey (2000), o campo de política pública apresenta-se quando diferentes atores, interesses e recursos, constrangidos pelo sistema político (polity), estabelecem-se na arena política (politics), mesmo a partir de compreensões diferenciadas a respeito do problema público, e atuam para formular alternativas e tomar decisões. A política pública apresenta-se como decisões públicas com vistas "às ações ou omissões, preventivas ou corretivas, destinadas a manter ou modificar a realidade de um ou vários setores da vida social, por meio da definição de objetivos e estratégias de atuação e da alocação dos recursos necessários para atingir os objetivos estabelecidos" (Saravia, 2006, pp. 28-29).

A CF de 1988 estabeleceu que as políticas públicas urbanísticas deveriam ser construídas com a participação de todos os entes federados, ou seja, de forma integrada. Em oposição à ideia do centralismo que acontecia em momento anterior à CF de 1988, existe um princípio organizacional denominado federalismo (Baldi, 1999) que pressupõe a distribuição territorial do poder (Elazar, 1987). É uma espécie de governança multinível ou interfederativa, em que cada ente detém uma porção garantida de poder e que não pode ser retirada pelos demais entes (Baldi, 1999). A governança metropolitana está diretamente ligada à discussão sobre o federalismo, visto tratar-se, exatamente, do "arranjo institucional que viabiliza o exercício de competências de mais de um ente, num espaço que vai além dos limites político-administrativos e territoriais" de um município (Santos, 2018, p. 473).

Vários autores, como Jones (1970), Meny e Thoenig (1992), Dye (1984) e Frey (2000), chamam o complexo processo de construção de políticas públicas como Ciclo de Políticas Públicas. Saravia e Ferrarezi (2007) propõem um ciclo para o processo de construção de políticas públicas, composto pela formalização de uma agenda, elaboração, formulação, implementação, execução, acompanhamento e avaliação de determinada política.

É importante destacar, nesse momento, que conceber e narrar o ciclo de política pública, chamando a atenção para suas etapas ou 
fases, é uma abordagem meramente didática, pois o processo de política pública não se estabelece cumprindo necessariamente uma ordem ou linearidade.

A agenda constitui-se quanto os fatos sociais são reconhecidos com o status de "problema público" (Kingdon, 2006; Fuks, 2000; Saravia, 2006; Cobb e Elder, 1995). O primeiro passo para o estabelecimento da agenda pública é o reconhecimento social que é dado a uma questão, a um assunto público por parte de atores influentes (Fuks, 2000). De acordo com Kingdon (2006, pp. 227-228), a definição das agendas passa por três elementos: pelos problemas, pela questão política e pela participação dos atores visíveis. A questão política ocorre com mudanças de governos, de novas configurações partidárias ou ideológicas, por meio de negociações políticas e pelo uso de indicadores, que podem identificar e justificar os problemas. Já os atores visíveis são aqueles que detêm considerável atenção da imprensa e do público, como, por exemplo, o presidente da república, membros do Congresso Nacional, a mídia e partidos políticos (Kingdon, 2006).

Existem também aqueles que não têm poder de influenciar o que entra na agenda, são os atores invisíveis, que podem ser acadêmicos e agentes públicos da burocracia do Estado, assim como movimentos sociais e organizações não governamentais que se inserem no processo de política pública (Fuks, 2000; Borges, 2013).

Quanto aos tipos de agenda, este trabalho aborda a perspectiva de Cobb e Elder (1995), autores que adotam a existência de dois tipos de agendas políticas, a agenda sistêmica e a institucional. Segundo esses autores, a agenda sistêmica origina-se em ocasiões de controvérsias políticas, e essas controvérsias envolvem questões das agendas sistêmicas locais, envoltas de normas, valores e ideologias, e numa "preocupação compartilhada" e na "percepção comum", dando sustentação à criação da agenda. Já a agenda governamental ou institucional evidencia os vieses estruturais e institucionais dentro do sistema e caracteriza-se como um conjunto de questões definidas como mais importantes por quem decide.

Após a formulação de políticas públicas, por meio de constituição de uma agenda, ocorre o processo de implementação dessas políticas. 0 verbo implementar, segundo Pressman e Wildavsky (1984), vem do levar algo a cabo, realizar, cumprir, executar. Para os autores, desde o princípio, esse termo refere-se à uma ação e necessita ter como objeto uma política pública.

Para Ohlweiler (2007), implementação de políticas públicas está relacionada com a efetividade da ação governamental para fazer acontecer os planos construídos. No entanto, para Cline (2000), existe o "problema de implementação", quando as políticas públicas não conseguem ser implementadas com sucesso. Um dos motivos, segundo o autor, está relacionado ao conflito de interesses. A solução para os problemas de implementação está ligada à cooperação dos participantes no processo, o que será possível mediante a construção de mecanismos que criem um contexto de cooperação entre os participantes.

A implementação corresponde "à execução de atividades [...] com vistas à obtenção de metas definidas no processo de formulação das políticas" (Silva e Melo, 2000, p. 4). Uma vez criada a política, presume-se um processo técnico de implementação, que deve ser precedido de um planejamento para a execução da 
política pública (Pressman e Wildavsky, 1984). No entanto, todo o ciclo de políticas públicas deve ser objeto de muito diálogo e cooperação entre os diferentes atores envolvidos, o que é essencial para o processo de implementação (Ramos, 1989; Cline, 2000).

Cabe observar que, para a implementação de qualquer política pública, faz-se necessária uma capacidade estatal, constituída com equipe técnica, normativas e instrumentos. Em uma RM, essa estrutura também é necessária (Borges, 2013). A falta de uma estrutura de gestão metropolitana na RM pode resultar que esse arranjo não consiga se colocar enquanto órgão de planejamento. Recursos, espaço físico próprio, corpo técnico de carreira, assim como um orçamento específico para essas RMs, são necessários a fim de atender às demandas do planejamento territorial (Cunha, 2016).

\section{Procedimentos metodológicos}

Atentando-se ao objetivo da pesquisa, optou-se por desenvolver o presente trabalho, epistemologicamente, por meio do construcionismo social, compondo histórias a partir de diálogos com diferentes atores dessa arena de política pública e mobilizando diferentes narrativas circunscritas a ela, sobre o vivido e o praticado, bem como a literatura sobre o tema abordado, colocando a pesquisa no movimento da construção social de realidades (Spink, 2003, Borges, 2013).

O construcionismo social pode ser associado a uma maneira de contar e produzir o mundo, e demonstra a importância da narrativa na construção do processo científico (Spink,
2003; Ibañez, 2001), e busca, por meio do contar histórias, conceber uma narrativa como produção de sentidos (Spink, 2013; Gergen, 1997). Na pesquisa concebida por essa base epistemológica, cabe, ao pesquisador, encontrar meios de recontar ou renarrar histórias socialmente construídas e dar visibilidade ao(s) sentido(s) que se encontra(m) oculto(s) no(s) registro(s) (Borges, 2013). O construcionismo social tem como base a dimensão de que não existe verdade nem uma única forma de explicar a realidade, nada é natural em sociedade, tudo é construído socialmente.

A metodologia utilizada para este estudo se estabelece como a abordagem qualitativa. Creswell (2010, p. 44) destaca: "a pesquisa qualitativa é exploratória e conveniente quando o pesquisador não conhece as variáveis importantes a serem examinadas", havendo um aprofundamento em relação à compreensão dos fenômenos sociais. A abordagem qualitativa tem como objeto de estudo "o nível dos significados, motivos, aspirações, atitudes, crenças e valores, que se expressam pela linguagem comum e na vida cotidiana" (Minayo e Sanches, 1993, p. 245). Nesse sentido, trata-se de um processo de produção de sentidos e não um ambiente (realidade) no qual o pesquisador se insere e apenas decodifica.

Com a revisão de literatura, o intuito foi contar, ao leitor, a história sobre a questão metropolitana no Brasil e o processo de criação de RMs. A coleta de dados teórico-empíricos deu-se em dois momentos. Primeiro, com uma pesquisa bibliográfica e documental, para a construção da evolução histórico-legal das RMs no Brasil. A mobilização das principais referências doutrinárias sobre o tema e a pesquisa documental incluíram documentos e legislação referentes à governança 
interfederativa utilizados na presente pesquisa como dados secundários, como, por exemplo, o Estatuto da Metrópole.

Em um segundo momento, ocorreram entrevistas semiestruturadas com atores que representam as organizações públicas que estão vinculadas ao tema de pesquisa, sendo eles: 1) Helena Pereira, ${ }^{1}$ integrante do Observatório das Metrópoles - Núcleo Maringá; 2) José da Silva, ex-deputado estadual, idealizador do projeto que criou a RMU; 3) João Bento, procurador do Ministério Público do Paraná, que abordou sua participação nos Fóruns Metropolitanos promovidos em outubro e novembro de 2015 pela Comissão de Assuntos Metropolitanos da Assembleia Legislativa do Paraná, que procurou discutir o Estatuto da Metrópole e também a necessidade de as RMs paranaenses se adequarem ao referido Estatuto para sua permanência ou extinção, bem como tratou da elaboração dos Planos de Desenvolvimento Urbano Integrado (PDUI); 4) Alcides Ferreira, do Paranacidade/Sedu; 5) Antônio Oliveira, o então prefeito do município de Umuarama, em 2012, época em que foi instituída a RMU; 6) Francisco Souza, o atual prefeito de Umuarama; 7) Afonso Santos, o prefeito do município $A$, um dos municípios mais próximo de Umuarama; e 8) Luiz Franco, prefeito do município $\mathrm{B}$, o mais distante da cidade-polo.

As entrevistas foram gravadas em áudio, após autorização, e transcritas posteriormente para apresentação e tratamento dos dados na forma de uma narrativa construída de modo relacional. A construção da narrativa na qual se tem a história do processo de criação e implementação da RMU tomou como base todas as narrativas produzidas com as entrevistas, documentos, registros e estudos técnicos, bem como normativas mobilizadas. Para a produção dessa inteligibilidade, foram tomados, como referência, os escritos de Laurence Bardin (Bardin, 1977), sobre análise de conteúdo, e de Peter Spink (Spink, 2003), sobre campo-tema.

Para a análise dos resultados, foram concebidas algumas categorias a partir do estudo empírico, sendo elas: interesse de acesso a recursos, interesse de status; interesse de legado e currículo político; interesse eleitoreiro; interesse imobiliário; e interesse de troca de favores.

Antes de o artigo avançar aos interesses políticos inscritos no processo de criação e implementação da RMU, cabe, primeiro, caracterizar a região metropolitana em questão, destacando seu desalinhamento em relação às normativas que orientam e legitimam a constituição do território metropolitana no Brasil.

\section{Caracterização da Região Metropolitana de Umuarama}

Antes de responder diretamente ao objetivo do presente trabalho, é fundamental conhecer a caracterização da RMU, iniciando pelo município-polo, Umuarama.

Distante aproximadamente $560 \mathrm{~km}$ da capital do estado e população estimada em 111.557 habitantes, Umuarama é o 18으 município mais populoso do estado e tem, como principais atividades, agricultura e pecuária de corte e a prestação de serviços (IBGE, 2018). A Figura 1 localiza o município de Umuarama e os demais municípios inscritos na RMU, concebendo o recorte metropolitano.

A RMU foi criada pela lei complementar estadual n. 149, de agosto de 2012, e teve como seu idealizador o ex-prefeito de Umuarama e ex-deputado estadual, José da Silva (Paraná, 
Figura 1 - Região Metropolitana de Umuarama

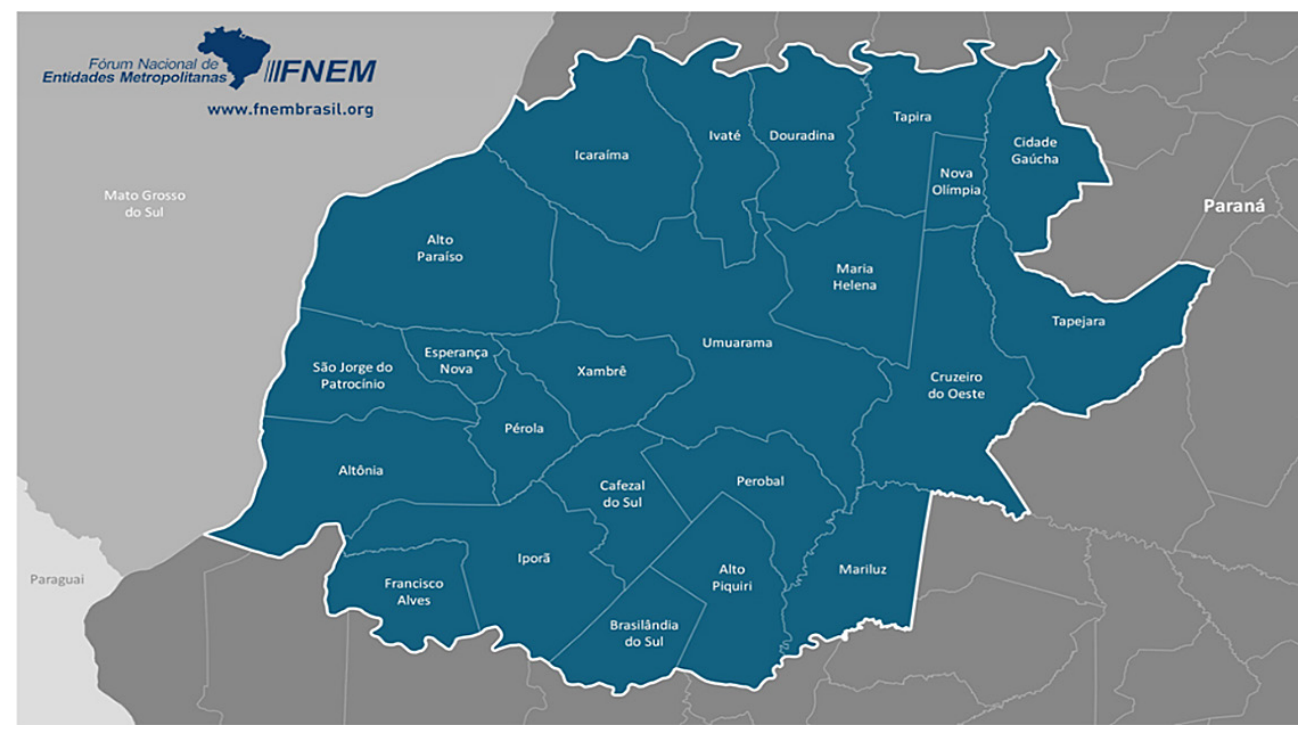

Fonte: FNEM (2018).

2012). A população estimada para a RMU, em 2019, segundo o IBGE, é de 313.794 habitantes. Segundo o Ipardes (2019), a RMU tem área territorial de $12.099,936 \mathrm{~km}^{2}$, o que representa cerca de $6 \%$ de todo o território do estado.

São 24 os municípios inscritos na RMU: Alto Paraíso, Alto Piquiri, Altônia, Brasilândia do Sul, Cafezal do Sul, Cidade Gaúcha, Cruzeiro do Oeste, Douradina, Esperança Nova, Francisco Alves, Icaraíma, Iporã, Ivaté, Maria Helena, Mariluz, Nova Olímpia, Perobal, Pérola, São Jorge do Patrocínio, Tapejara, Tapira, Tuneiras do Oeste, Umuarama e Xambrê. Uma primeira observação é que 13, dos 24 municípios inscritos na RMU, se encontram a mais de $50 \mathrm{~km}$ da cidade-polo, Umuarama.
Uma tensão que se estabeleceu no processo de construção da inteligibilidade proposta pelo presente artigo envolveu problematizar se a RMU atende aos requisitos exigidos pelo Estatuto da Metrópole, embora ela tenha sido constituída em 2012, data anterior à referida normativa.

Sabe-se que, pelas normativas vigentes, para que uma região se caracterize como RM, é necessário que a cidade-polo tenha influência de uma metrópole ou de um centro regional, isto é, tenha influência nacional ou sobre uma região, ou que se configure, ao menos, como uma capital regional nível $B$, conforme o parágrafo único do art. 2ํ da lei n. 13.089, de 2015. 
Para tanto, foram mobilizados estudos realizados pelo IBGE: o APCUB (2016) e o Regic (IBGE, 2008 e 2020); e pela Sedu: o PDUR (2017 e 2018); para a análise da interação urbana da RMU na presente pesquisa.

Considerando os Regics, de 2008 e 2020, o nível de centralidade ou influência do município de Umuarama está na dimensão de um Centro Sub-regional A (IBGE, 2008 e 2020). Nesse primeiro requisito, observa-se que a RMU não se enquadra como RM. Segundo o IBGE (2016), os únicos dois municípios da RMU que constam do referido estudo são Umuarama, cidade-polo, e o município de Maria Helena, os quais apresentaram nível de integração mais significante, compondo um arranjo populacional (AP).

Segundo o IBGE (ibid.), para que se configure uma forte intensidade relativa aos movimentos pendulares para trabalho e estudo, é necessário que o índice de integração seja igual ou superior a 0,17 para todos os municípios que compõem a RM. Observou-se, no estudo do IBGE, que o município de Maria Helena atingiu o valor mínimo que identifica movimentos pendulares entre o referido município e Umuarama. No entanto, os demais municípios inscritos na RMU não constam do estudo do IBGE, pois, de acordo com o IBGE (ibid.), todos os municípios que não alcançaram o índice mínimo de integração não foram listados na apresentação dos dados.

Um segundo requisito, ainda de acordo com o IBGE (ibid.), é que deve existir forte intensidade absoluta dos movimentos pendulares para trabalho e estudo - quando o volume absoluto de pessoas que se deslocam para trabalho e estudo, entre A e B, é igual ou superior a 10.000 pessoas. Segundo o estudo realizado pelo IBGE, apenas 1.484 pessoas trabalham e estudam em outros municípios do arranjo populacional de Umuarama.

Com base nos dados levantados, observa-se que os municípios que compõem a RMU não têm a integração exigida pelo Estatuto da Metrópole, para uma RM. Embora os municípios de Umuarama e Maria Helena apresentam movimentos pendulares, não existe níveis elevados de interdependência entre esses dois municípios em relação aos demais inscritos na RMU. Não foi constatado elevada concentração urbana, segundo os critérios do IBGE e, por último, a cidade-polo, Umuarama, não se qualifica como capital regional $B$.

Segundo o Ipardes (2017, p. 9), a Sedu manifestou-se contrária à manutenção de todas as RMs instituídas no estado do Paraná, a partir de 2012. Com exceção da RM de Cascavel, tomando-se como base o Estatuto da Metrópole, todas essas RMs não atendem a seus critérios.

Sobre o fato de a RMU ter sido instituída antes do Estatuto da Metrópole, Cunha (2016, p. 6) afirmou que a falta de critérios na CF de 1988, no que se refere à definição do que é ou não metropolitano, e o fato de ter dado aos estados a prerrogativa de instituir suas RMs abriram "um leque de possibilidades de institucionalização de Regiões Metropolitanas em que o processo de metropolização muitas vezes não está presente, como no caso de Umuarama, institucionalizada em 2012". Portanto, também é tarefa das assembleias legislativas estaduais aprovar, por meio de projeto de lei complementar, a extinção de uma RM. Sendo assim, a Sedu encaminhou, à Assembleia Legislativa do Estado do Paraná, "proposta de lei estadual complementar para a extinção das quatro regiões metropolitanas que não mais seriam entendidas como tal", o que incluiu a RMU (PDUR, 2017, p. 161). 
Portanto, após apresentadas tais ponderações, o presente artigo volta-se a responder a principal pergunta de pesquisa: quais foram as motivações e os interesses que levaram a criação e manutenção da RMU, visto que os critérios técnicos não foram atendidos?

\section{Os interesses políticos inscritos no processo de criação e implementação da RMU}

Como se optou pela base epistemológica do construcionismo social para o desenvolvimento da pesquisa, temos como resultado a construção de uma inteligibilidade como a principal narrativa, a qual expressa os resultados da pesquisa. Trata-se de uma história que tem autoria, e ela não seria a mesma história se fosse contada por outra pessoa. No contar a história, existe um processo construído. Qual processo? Optou-se por contar essa história de modo não linear, a partir de uma escolha de temas e argumentos conforme foram sendo acessados em diferentes narrativas.

Tudo começa pela política pública, que conforme abordado, é o conjunto de ações dos governos que produzem efeitos específicos, que influenciam a vida dos cidadãos e têm como objetivo resolver problemas de interesse público. De acordo com as narrativas acessadas, a criação da RMU não teve como objetivo a resolução de problemas de interesse público. Não é possível identificar que ela se enquadra como uma legítima política pública, pois, embora alguns atores manifestem que seria um avanço para os municípios, os interesses políticos partidários, de status, e imobiliários foram identificados nas várias narrativas como justificativa da criação da RMU e não os interesses públicos de fato, constituídos como problema público e significados socialmente.

Conforme as narrativas, a RMU entra na agenda por iniciativa de um deputado, José da Silva, responsável pelo projeto de lei que viria a criar a referida região metropolitana. Trata-se de um ator visível no processo de constituição de agenda. 0 discurso era propiciar o desenvolvimento da região: "Foi pensando nesse desenvolvimento regional que eu criei a Região Metropolitana de Umuarama, porque todos os benefícios que vão para as capitais viriam para Umuarama [...] incentivos em infraestrutura, em saneamento básico" (José da Silva, ex-deputado estadual). "A criação da Região Metropolitana de Umuarama se justificou devido ser a região mais enfraquecida do Estado, e sem apoio do governo estadual [...] seria a redenção dessa região" (Antônio Oliveira, ex-prefeito de Umuarama).

No presente estudo, optou-se pelos tipos de agenda defendidos por Cobb e Elder (1995): a agenda sistêmica e a agenda institucional. Segundo as narrativas, a questão da criação da RMU entra na agenda institucional quando seu projeto de criação é formalizado na Assembleia Legislativa do Paraná. Segundo Alcides Ferreira e o Ipardes (2017), mesmo tendo a Sedu dado parecer negativo para a criação da RMU, o ex-deputado José da Silva sustentou, na assembleia legislativa, o referido projeto contra o secretário da Sedu, Cesar Silvestre, e não cedeu à pressão, argumentando que o secretário não pressionou os comitês técnicos da Sedu para que se alterasse o parecer para favorável, demonstrando uma controvérsia política (Alcides Ferreira, Sedu). 
Mas é necessário ir em busca de uma resposta à maior das inquietações do presente estudo, que diz respeito aos interesses políticos inscritos no processo que influenciaram a criação e a implementação da RMU, presentes na agenda sistêmica. A partir das narrativas auferidas, observa-se um movimento de construção de interesses das lideranças políticas, haja vista o vislumbrar dos ganhos que os "seus municípios" passariam a ter com a RMU. A esse respeito, João Bento, procurador do Ministério Público, argumentou o seguinte: "As pessoas acham que, criando uma $R M$, elas vão gerar de fato ganhos, vão trazer recursos para sua região".

Nesse processo de construção do projeto de lei, fica evidente, por meio das narrativas, a expectativa dos benefícios para os municípios, e que, até pelo criador do referido projeto, esperava-se um aumento de empregos, pelo deslocamento de empresas para os municípios que ingressassem na RMU. Além disso, para o ex-prefeito de Umuarama, Antônio Oliveira, por ser uma RM, os municípios poderiam integrar o transporte coletivo intermunicipal e as tarifas de ligações telefônicas.

Durante as entrevistas, observou-se um ponto de divergência, quando os interlocutores foram questionados a respeito do aspecto conceitual: o que é uma RM e o que a caracteriza? Os prefeitos acessados, o ex-prefeito de Umuarama, Antônio Oliveira, e o atual prefeito de Umuarama, Francisco Souza, têm mais informações e conhecimentos sobre alguns termos técnicos, no que se refere ao tema metropolitano, em virtude da posição como gestores da cidade-polo da RMU; já os demais prefeitos acessados mostraram ter pouco ou nenhum conhecimento sobre o assunto. Isso denota que a questão metropolitana não é dialogada pelos municípios que compõem a RMU. Existe um vazio em termos de alinhamento metropolitano, por não haver um pensar e planejar o território de modo integrado.

Quando questionados se a RMU possuía as características para ser uma RM, tanto o atual como o gestor anterior da cidade-polo afirmaram que a região de Umuarama não as possuía. Helena Pereira, do Observatório das Metrópoles, João Bento, do Ministério Público, e Alcides Ferreira, da Sedu, também concordam que a RMU não tem as características necessárias de uma RM.

Em relação aos interesses, trata-se de um processo que começa a ser construído por meio do ex-deputado estadual José da Silva, a partir de uma necessidade ou de um desejo de deixar um legado, de deixar um registro no seu currículo e de vender um status, possibilidades aos municípios, no que diz respeito aos anseios por recursos. "Foi uma grande emoção ter um projeto dessa envergadura sendo aprovado no estado do Paraná [...] esse foi o grande feito desse projeto, que eu já me realizei como deputado" (José da Silva, ex-deputado estadual). Helena Pereira afirma que uma RM propiciaria tanto ao deputado, quanto ao prefeito, a inclusão do feito em seus currículos. Para Francisco Souza, prefeito de Umuarama, a RMU "foi questão política", visando a aumentar os currículos dos parlamentares.

Outros interesses identificados nas narrativas foram de ordem político-eleitoreiros. José da Silva afirmou: "Você sabe que os governos, tanto estadual como federal, investem em grandes aglomerados, onde está o grande número de 'eleitores' [...] essa é a moeda do político! É voto, é voto!". Para Helena Pereira, "a principal questão é eleitoral". Segundo ela, os interesses têm motivação de construção 
de palanque eleitoral nos municípios; além de realizar campanha para o deputado nas eleições posteriores, os prefeitos também têm "interesse eleitoral".

Outro motivo de interesse em se fazer parte de uma RM foi o de acessar recursos: "os interesses são de o governo federal pôr mais recursos, principalmente a fundo perdido". Segundo José da Silva, e mais três dos quatro prefeitos entrevistados, imagina-se que, fazendo parte de uma RM, o município vai acessar melhores condições para realizar investimento por parte de recursos da União e do estado. Porém, conforme abordado na revisão de literatura, não existe um financiamento metropolitano. Segundo Helena Pereira, isso demonstra ignorância dos gestores em imaginar que os municípios, pelo fato de pertencerem a uma RM, teriam direitos a acessar recursos.

Além desses interesses até aqui abordados, um dos motivos principais para a criação da RMU foi o interesse imobiliário. Francisco Souza mencionou o interesse pela criação da RMU voltado para o programa habitacional do governo federal: "vislumbraram esse desconto no Minha Casa Minha Vida, porque daria um boom, inclusive Umuarama foi beneficiada por isso... já se calcularam aqui em milhões". Para o executivo da Sedu, Alcides Ferreira, o interesse na criação de novas RMs foi, em primeiro lugar, imobiliário. Segundo ele, o município, ao pertencer a uma RM, receberia um subsídio de $R \$ 45.000,00$ a mais, por imóvel, para sua aquisição, pelo programa de habitação do governo federal - PMCMV. Segundo o executivo da Sedu, os prefeitos acabaram se mobilizando devido à pressão dos empresários locais que queriam fazer novos loteamentos e casas. E, conforme o ex-deputado José da Silva, foram mais de 800 milhões de reais em subsídios aos munícipes que contrataram o financiamento habitacional do PMCMV, e tais valores puderam permanecer na RMU, movimentando, assim, a economia local.

Outro motivador para a criação de RMs, também acessado pela revisão de literatura, refere-se ao status. Nas narrativas, esse desejo também foi captado. Para Helena Pereira, do Observatório das Metrópoles, "como ninguém sabe o que significa ser incluído numa RM, a narrativa da inclusão na RM garante status, porque o prefeito bate no peito e diz 'fui eu quem conseguiu incluir o nosso município na $R M U^{\prime \prime \prime}$. Segundo João Bento, não seria uma placa que garantiria o funcionamento da RM. Para o procurador, houve uma "glamorização" ou "fetiche metropolitano", o que elevou o interesse e, consequentemente, o aumento no número de RMs.

$E$, finalizando essa construção de inteligibilidade sobre os "interesses políticos", a troca de favores foi outro motivo acessado nas narrativas. Helena Pereira descreve que os prefeitos que estabeleceram um acordo com o proponente do projeto de lei da RM "ficavam como devedores a realizar campanha na próxima eleição pra esse deputado em seus municípios". Em relação a essa prática, observa-se o compromisso político firmado entre o então governador do estado com o ex-deputado José da Silva, ao sancionar o projeto de lei complementar da RMU: "E o governador Beto Richa então sancionou essa lei que tinha um compromisso comigo, e que se eu aprovasse a lei na assembleia, que ele sancionaria. E foi o que aconteceu" (José da Silva).

Sobre essa troca de favores, Alcides Ferreira elucida que o então governador Beto Richa, num primeiro momento, acatou o parecer de ordem técnica desfavorável da Sedu, o que 
incluía a criação da RMU, mas, posteriormente, visto que necessitava de apoio dos prefeitos, sancionou as leis que aprovaram a criação das cinco últimas RMs paranaenses. Segundo Alcides Ferreira, o governador aprovou as RMs porque o "interesse político falou mais alto".

É pertinente destacar que nenhum estudo que justificasse a instituição da referida RMU, abordando as FPICs, por exemplo, foi feito antecipadamente. No entanto, segundo José da Silva, foi intenso o trabalho nos "bastidores" da Assembleia Legislativa do Paraná. De acordo com o ex-parlamentar, ele teve que trocar, por algumas vezes, os relatores nas comissões pelas quais o seu projeto tramitou. E, de acordo Alcides Ferreira, a Sedu negou o parecer para a criação da RMU, conforme já abordado.

Após a criação da RMU, segundo Alcides Ferreira e Francisco Souza, alguns municípios inscritos na Região Metropolitana de Umuarama começaram a questionar a impossibilidade de acesso aos recursos da Fundação Nacional de Saúde (Funasa). ${ }^{2}$ Para Alcides Ferreira, muitos prefeitos, ao tomarem conhecimento dos critérios de elegibilidade aos recursos da Funasa, começaram a pleitear a saída da RM. Para o secretário executivo da Sedu, o mesmo que justificou a criação da RMU, um "casuísmo", vai justificar também a sua extinção, devido à impossibilidade de acesso a recursos da Funasa, a fundo perdido, para investimento em saneamento.

João Bento e José da Silva também explicam outro desinteresse por parte dos municípios na RMU. Os entrevistados argumentaram sobre a perda da autonomia da gestão do território por parte dos municípios, na medida em que cada município, pelo fato de estar inscrito na RMU, precisaria agora se submeter ao colegiado. "Para as decisões da RM, vou ter que ceder espaço para a minha autonomia... a decisão vai ser da governança", ponderou João Bento. Já o ex-deputado disse por três vezes, em diferentes momentos, que a perda da autonomia ou, como ele chamou, "perda de poder" sobre os loteamentos foi um dos temores dos prefeitos.

Constatou-se, em todas as narrativas (documentos e entrevistas), que a RMU não foi implementada. No entanto, alguns programas de governo passaram a ser viabilizados na região de Umuarama devido à criação da RMU, como o PMCMV. Foram vários os projetos desse programa habitacional pulverizados na RMU, os quais somente se estabeleceram por essa RM se encontrar constituída, o que permitiu acesso ao financiamento de imóveis com valores e subsídios maiores, conforme já destacado.

A partir das histórias contadas, no que tange à gestão governança e governo metropolitanos, nada disso acontece na RMU. 0 governo metropolitano estabelecer-se-ia a partir da coordenadoria da Região Metropolitana. A gestão, por sua vez, estabelecer-se-ia por meios das políticas públicas metropolitanas implementadas na RMU. Já a governança se constituiria pelos espaços decisórios exercidos por atores de bases do governo, do Estado e da sociedade civil, envolvendo conselhos, câmaras técnicas e comunidade epistêmicas, por exemplo. Por não se efetivar nenhuma dessas práticas, isso fortalece a dimensão de ter apenas interesses pela criação e não pela implementação da RMU.

João Bento, procurador do Ministério Público, comenta algo que foi totalmente desconsiderado durante o processo de criação da RMU. Ele argumenta: "a Região Metropolitana não é geopolítica, ela é 'fática'. Ou ela 
acontece ou ela não acontece". Para que um projeto de lei complementar faça todo o percurso até ser sancionado, uma RM de fato já existe mesmo antes da sua instituição.

Conforme contado nessa história, os interesses políticos influenciaram o processo que levou à criação da RMU. Agora caberia, a esses mesmos atores políticos visíveis, a decisão pela correção do equívoco conceitual; ou, como disse Alcides Ferreira, o "engano semântico" ocorrido quando da criação da RMU? Os parlamentares só farão isso ao aprovarem um projeto de lei complementar estadual que promova a extinção da RMU e das demais RMs que não atendem aos critérios delimitados pelo Estatuto da Metrópole.

\section{Considerações finais}

A decisão tomada por criar a RMU foi com base em interesses políticos, eleitoreiros, imobiliários e desejo de status, e não com base em elementos técnicos e conceituais e muito menos tendo como referência problemas públicos legitimados em uma agenda sistêmica. Observa-se que não ocorreu a implementação da RMU porque o objetivo não era a implementação, era apenas a criação para, por exemplo, acessar os recursos do governo federal do PMCMV, sendo condição o status de RM.

Numa das narrativas, observa-se que uma das justificativas para a criação da RMU foi atender a uma demanda popular, como uma agenda social, com o acesso ao programa habitacional Minha Casa Minha Vida. Mas o que esteve por trás é uma elite econômica, interesses econômicos/imobiliários, utilizando de uma configuração territorial para acessar recursos, tendo em vista que o PMCMV dimensionou a política de acesso a recursos, segmentando por municípios e regiões.

0 processo de criação da RMU não partiu dos atores invisíveis, de movimento sociais marginalizados, tentando chamar a atenção do poder público ou mobilizar a mídia por transportes melhores e mais integrados, ou mesmo por uma melhor condição de acesso às habitações. 0 processo partiu dos atores visíveis, interessados politicamente nos resultados.

Em tese, as políticas públicas são criadas a partir da necessidade de solucionar um problema público. No entanto, não existe um problema público que legitime a criação da RMU. O pensar a RMU existiu justamente no intuito de deixar um legado político, para o deputado e para os prefeitos, e como uma forma de acessar recursos. Há uma inversão da lógica do pensar as políticas públicas, inclusive sob a ótica do Estatuto da Metrópole.

0 que se pode constatar é que a RMU não se caracteriza como uma RM, não atende aos requisitos do Estatuto da Metrópole. Embora tenha sido instituída antes da sanção do referido Estatuto, já existiam outras exigências nas legislações, como as FPICs que já se encontravam na CF de 1988. Não existem FPICs que sustentem a criação da RMU e, nesse âmbito, nem ao menos houve um estudo para tratar da legitimidade de criação da referida RM.

A partir desses resultados de pesquisa, é fundamental destacar que não existe um fundo de desenvolvimento metropolitano, seja no Brasil ou no Paraná, questão elementar para efetivar a política almejada pelo Estatuto da Metrópole. Além de o Estatuto não prever especificamente um financiamento metropolitano, desobrigando a União de dar apoio financeiro as RMs, no caso específico do estado 
do Paraná, a legislação estadual também não previu a criação obrigatória de um fundo metropolitano para as RMs.

Outra modalidade de arranjo, com propósito de executar ações de interesse comum, são os consórcios públicos. Estes são arranjos institucionais voluntários, formados pela associação de mais de um ente da federação. A busca exclusiva por um título de Região Metropolitana tem levado muitas regiões a desconsiderarem outros arranjos regionais que poderiam ser mais eficientes ao atendimento do interesse público. Esses arranjos institucionais, como os consórcios, por exemplo, poderiam atender aos interesses públicos para a Região de Umuarama? Essa pergunta se estabelece como sugestão para futuros estudos, o que envolve pensar a questão dos consórcios como instrumento de cooperação intermunicipal e interfederativa e que servem aos municípios que integram as regiões metropolitanas, principalmente aquelas que não atendem aos critérios estabelecidos pelo Estatuto da Metrópole.

\section{[I] https://orcid.org/0000-0003-3544-9046}

Universidade Estadual de Maringá, Departamento de Administração, Programa de Mestrado em Administração. Maringá, PR/Brasil.

renato.oliver@outlook.com.br

\section{[II] https://orcid.org/0000-0001-6008-9738}

Universidade Estadual de Maringá, Departamento de Administração, Programas de Pós-Graduação em Políticas Públicas e de Pós-Graduação em Administração. Maringá, PR/Brasil.

waborges@uem.br

\section{Notas}

(1) Os nomes de todos os atores entrevistados foram trocados, a fim de preservar a privacidade das pessoas envolvidas.

(2) A Funasa é uma fundação pública, vinculada ao Ministério da Saúde, que prevê recursos na área de saneamento básico para municípios com até 50 mil habitantes.

Segundo a portaria n. 1.035, de 8 de agosto de 2017, do Ministério da Saúde, os municípios que fazem parte de regiões metropolitanas, mesmo aqueles que possuem até 50 mil habitantes, não podem se beneficiar dos recursos previstos pela Funasa (Brasil, 2017). 


\section{Referências}

ABRUCIO, F. L. (2010). “Federalismo e Políticas Públicas: o impacto das relações intergovernamentais no Brasil”. In: LEVY, E.; MEDEIROS, P. C. (orgs.). Construindo uma Nova Gestão Pública. Natal SEARHH/RN.

APCUB - ARRANJOS POPULACIONAIS E CONCENTRAÇÕES URBANAS NO BRASIL (2016). Rio de Janeiro, IBGE. Disponível em: http://www.ibge.gov.br/apps/arranjos_populacionais/2015/pdf/publicacao. pdf. Acesso em: 8 nov 2018.

ASCHER, F. (1995). Métapolis ou l'avenir des villes. Paris, Éditions Odile Jacob.

AZEVEDO, S.; MARES GUIA, V. R. (2000). Governança Metropolitana e Reforma do Estado: o caso de Belo Horizonte. Revista Brasileira de Estudos Urbanos e Regionais, n. 3, pp. 131-144.

BALBIM, R. et al. (2012). “Desafios contemporâneos na gestão metropolitana”. In: LINHARES, P. de T. F. (org.). Federalismo à brasileira. Brasília, Ipea.

BALDI, B. (1999). Beyond the federal-unitary dichotomy. Working Papers 99-7. Berkeley, Institute of Governmental Studies, University of California.

BARBOSA, K. S. (2010). Por que a gestão da Região Metropolitana do Vale do Aço não sai do papel? Dissertação de mestrado. Belo Horizonte, Universidade Federal de Minas Gerais.

BARDIN, L. (1977). Análise de conteúdo. Lisboa, Edições 70.

BERNARDES, L. et al. (1971). A Institucionalização das Regiões Metropolitanas. Revista Administração Pública. Rio de Janeiro, v. 5, n. 1, pp. 117-148.

BORGES, W. A. (2013). Gestão Metropolitana: sua construção a partir de duas experiências de associativismo territorial na Região Metropolitana de Curitiba. Tese de doutorado. São Paulo, Fundação Getúlio Vargas.

BRASIL (1988). Constituição da República Federativa do Brasil. Brasília, DF, Senado Federal. Disponível em: http://www.planalto.gov.br/ccivil_03/constituicao/constituicaocompilado.htm. Acesso em: 22 set 2018 .

(2001). Lei n. 10.257, de 10 de julho. Institui o Estatuto da Cidade. Diário Oficial da União. Brasília, DF. Disponível em: http://www.planalto.gov.br/ccivil_03/leis/leis_2001/I10257.htm. Acesso em: 30 out 2018.

(2015). Lei n. 13.089, de 12 de janeiro. Institui o Estatuto da Metrópole. Diário Oficial da União. Brasília, DF. Disponível em: http://www.planalto.gov.br/ ccivil_03/_ato2015-2018/2015/lei/ I13089.htm. Acesso em: 14 set 2018.

(2017). Ministério da Saúde. Portaria n. 1.035, de 8 de agosto. Aprova os critérios e os procedimentos básicos para aplicação de recursos orçamentários e financeiros, do Programa de Resíduos Sólidos Urbanos. Diário Oficial da União. Brasília, DF, 9 ago. Disponível em: http://bvsms. saude.gov.br/bvs/saudelegis/funasa/2017/prt1035_09_08_2017. html. Acesso em: 15 dez 2019.

CARRERA-FREITAS, R. (2017). A descentralização como estratégia democrática para o desenvolvimento: a Região Metropolitana de Salvador frente a outras experiências de gestão compartilhada. Tese de doutorado. Salvador, Universidade Católica do Salvador. 
CARVALHO, S. N. (2001). Estatuto da Cidade: aspectos políticos e técnicos do Plano Diretor. São Paulo em Perspectiva. São Paulo, v. 15, n. 4, pp. 130-135.

CLINE, K. D. (2000). Defining the Implementation Problem: organizational management versus cooperation. Journal of Public Administration Research and Theory. Oxford, v. 10, n. 3, pp. 551- 571.

CNPq - Conselho Nacional de Desenvolvimento Científico e Tecnológico (2009). Arranjos institucionais para a gestão metropolitana. Rio de Janeiro, CNPq.

COBB, R. W.; ELDER, C. D. (1995). “Issues and agendas”. In: THEODOULOU, S.; CAHN, M. A. (orgs.). Public policy: the essential readings. Upper Saddle River/NJ, Prentice Hall.

CRESWELL, J. W. (2010). Projeto de pesquisa métodos qualitativo, quantitativo e misto. Porto Alegre, Artmed.

CUNHA, F. C. A. (2014). Regiões Metropolitanas Paranaenses: descompasso entre espacialidade e institucionalidade e a necessidade de uma reforma institucional. Revista Paranaense de Desenvolvimento Econômico. Curitiba, Ipardes, v. 35, n. 127, pp. 181-202.

(2016). A região como fruto de enunciados políticos e o descompasso entre institucionalidade e espacialidade nas Regiões Metropolitanas de Londrina e Maringá. Revista Formação (online), v. 3, n. 23, pp. 5-22.

DYE, T. R. (1984). Policy Analysis: what governments do, why they do it, and what difference it makes. Tuscaloosa, University of Alabama Press.

ELAZAR, D. J. (1987). Exploring federalism. Tuscaloosa, University of Alabama Press.

FERNANDES JUNIOR, E. (2003). O elo perdido: o desafio da gestão metropolitana. Fórum de Direito Urbano e Ambiental. Belo Horizonte, ano 2, n. 12, pp. 1191-1195.

(2004). Gestão metropolitana. Cadernos de Escola da Legislatura. Belo Horizonte, n. 12, v. 7, pp. 68-87.

FERNANDES, A. S. A.; ARAÚJO, S. M. V. G. (2015). A criação de municípios e a formalização de regiões metropolitanas: os desafios da coordenação federativa. Urbe - Revista Brasileira de Gestão Urbana, v. 7, n. 3, pp. 295-309.

FNEM - Fórum Nacional de Entidades Metropolitanas (2018). Conheça as regiões metropolitanas do estado. Disponível em: http://fnembrasil.org/pr/. Acesso em: 20 nov 2018.

FREY, K. (2000). Políticas públicas: um debate conceitual e reflexões referentes à prática da análise de políticas públicas no Brasil. Planejamento e Políticas Públicas. Brasília, n. 21, pp. 211-259.

FUKS, M. (2000). Definição da agenda, debate público e problemas sociais: uma perspectiva argumentativa da dinâmica do conflito social. BID, n. 49, pp. 79-94.

GERGEN, K. J. (1997). The place of the psyche in a constructed world. Theory Psychol, v. 7, n. 6, pp. 723-746.

GRAU, E. R. (1974). Regiões metropolitanas: regime jurídico. São Paulo, José Bushatsky.

(1975). Análise, crítica e implementação da legislação metropolitana. Revista Brasileira de Estudos Políticos. Belo Horizonte, v. 40, pp. 25-48.

IBAÑEZ, T. (2001). Municiones para disidentes: realidad, verdad, política. Barcelona, Gedisa. 
IBGE - Instituto Brasileiro de Geografia e Estatística (2008). Regiões de Influência das Cidades 2007. Rio de Janeiro. Disponível em: https://www. mma.gov.br/estruturas/PZEE/_arquivos/regic_28. pdf. Acesso em: 11 nov 2019.

(2010). Brasília - DF. População do Brasil é de 190.732.694 pessoas. In: Censo. Disponível em: http://censo2010.ibge.gov.br/noticias-censo.html?view=noticia; $i d=3 ;$ idnoticia=1766; busca=1; $t=$ censo-2010-populacao-brasil-190-732-694-pessoas. Acesso em: 28 set 2018.

(2016). Arranjos populacionais e concentrações urbanas do Brasil. Rio de Janeiro. Disponível em: https://biblioteca.ibge.gov.br/visualizacao/livros/liv99700.pdf. Acesso em: 11 nov 2019.

(2018). Unidades Territoriais do Nível Região Metropolitana. Disponível em: https://sidra.ibge. gov.br/ territorio\#/N7. Acesso em: 12 nov 2018.

(2020). Regiões de Influência das Cidades 2018. Rio de Janeiro. Disponível em: https:// biblioteca.ibge.gov.br/visualizacao/livros/liv101728.pdf. Acesso em: 12 dez 2020.

IPARDES - Instituto Paranaense de Desenvolvimento Econômico e Social (2019). Perfil da Região Metropolitana de Umuarama. Disponível em: http://www.ipardes.gov.br/perfil_municipal/ MontaPerfil.php?codlocal=925\&btOk=ok. Acesso em: 1o maio 2020.

JONES, C. (1970). Introduction to the study of public policy. Belmont, CA, Wadsworth.

KINGDON, J. (2006). "Como chega a hora de uma ideia?” In: SARAVIA, E.; FERRAREZI, E. Políticas Públicas: coletânea. Brasília, DF, Enap, v. 1.

KLINK, J. J. (2009). Regionalismo e reestruturação urbana: uma perspectiva brasileira de governança metropolitana. Educação. Porto Alegre, v. 32, n. 2, pp. 217-226.

MACHADO, A. V. et al. (2016). O fetiche metropolitano: colocando as ideias em ordem com o Estatuto da Metrópole. Revista Jurídica do Ministério Público do Estado do Paraná. Curitiba. ano 3, n. 5, pp. 27-41.

MARGUTI, B. O.; COSTA, M. A.; FAVARÃO, C. B. (orgs.) (2018). Brasil metropolitano em foco: desafios à implementação do Estatuto da Metrópole. Brasília, Ipea.

MENY, I.; THOENIG , J. C. (1992). Las políticas públicas. Barcelona, Ariel.

MINAYO, M. C. S.; SANCHES, O. (1993). Quantitativo-qualitativo: oposição ou complementaridade. Cadernos de Saúde Pública, v. 9, n. 3, pp. 239-262.

MORAES, S. T.; GUARDA, A.; ZACCHI, G. S. (2018). A caracterização das Regiões Metropolitanas catarinenses e o Estatuto da Metrópole. Geosul. Florianópolis, v. 33, n. 67, pp. 38-60.

MOURA, R.; FIRKOWSKI, O. L. C. (2001). Metrópoles e regiões metropolitanas: o que isso tem em comum? In: IX ENCONTRO NACIONAL DA ANPUR. Anais... Rio de Janeiro, v. 1, maio.

MOURA, R.; HOSHINO, T. de A. P. (2015). Estatuto da metrópole: enfim, aprovado! Mas o que oferece à metropolização brasileira? Informativo Observatório das Metrópoles. Rio de Janeiro, pp. 1-14.

OBSERVATÓRIO DAS METRÓPOLES/IPPUR/FASE (2008). Novas Governanças para as Áreas Metropolitanas o Panorama Internacional e as Perspectivas para o Caso Brasileiro. Rio de Janeiro. Disponível em: http://www.observatoriodasmetropoles.ufrj.br/relatorio_Klink.pdf. Acesso em: 13 nov 2018.

OHLWEILER, L. (2007). A construção e implementação de políticas públicas: desafios do Direito Administrativo moderno. Verba Juris, ano 6, n. 6. 
PARANÁ. (2012). Lei complementar n. 149 de 22 de agosto. Diário Oficial n. 8782 de 22 de agosto. Disponível em: https://www.legislacao.pr.gov.br/legislacao/pesquisarAto .do?action=exibir\&co dAto=73373\&indice=1\&totalRegistros=5. Acesso em: 27 jan 2019.

PDUR - Política de Desenvolvimento Urbano e Regional para o estado do Paraná (2017). Curitiba, Sedu. Disponível em: http://www.paranacidade.org.br/arquivos/File/PDUR/PDUR_ volume_1_20200310.pdf. Acesso em: 2 jul 2019.

(2018). Curitiba, Sedu. Disponível em: http://www.paranacidade.org.br/arquivos/File/PDUR/ PDUR_volume_2.pdf. Acesso em: 13 dez 2019.

PRESSMAN, J. L.; WILDAVSKY, A. (1984). Implementation. Berkeley, University of California.

RAMOS, A. G. (1989). A nova ciência das organizações: uma reconceituação da riqueza das nações. Rio de Janeiro, Editora da FGV.

SANTOS, A. E.; PEIXINHO, D. M. (2015). Processo de conurbação: elementos espaciais do fenômeno em área não metropolitana. Estudos Geográficos: Revista Eletrônica de Geografia. Rio Claro, jan/jun, pp. 35-52.

SANTOS, M. O. (2018). "Interpretando o Estatuto da Metrópole: comentários sobre a lei n. 13.089/2015". In: MARGUTI, B. O.; COSTA M. A.; FAVARÃO C. B. (orgs.). Brasil metropolitano em foco: desafios à implementação do Estatuto da Metrópole. Brasília, Ipea.

SARAVIA, E. (2006). "Introdução à teoria da política pública”. In: SARAVIA, E.; FERRAREZI, E. (orgs.) Políticas Públicas: coletânea. Brasília, Enap, v. 1.

SARAVIA, E.; FERRAREZI, E. (2007). Políticas Públicas: coletânea. Brasília, Enap, v. 1.

SECCHI, L. (2010). Políticas públicas: conceitos, esquemas de análise, casos práticos. São Paulo, Cengage Learning.

SILVA, P. L. B.; MELO, M. A. B. (2000). O processo de implementação de políticas públicas no Brasil: características e determinantes da avaliação de programas e projetos. Caderno NEPP. Campinas, Unicamp, n. 48, pp. 1-16.

SOUZA, C. (2003). Regiões metropolitanas: condicionantes do regime político. Lua Nova, v. 59, pp. $137-158$.

SPINK, M. J. (2013). “Produção de sentidos no cotidiano: uma abordagem teórico-metodológica para análise das práticas discursivas”. In: SPINK, M. J. (org.) Práticas discursivas e produção de sentidos no cotidiano: aproximações teóricas e metodológicas. Edição virtual.

SPINK, P. K. (2003). Pesquisa de campo em Psicologia Social: uma perspectiva pós construcionista. Psicologia e Sociedade. Belo Horizonte, v. 15, n. 2, pp. 18-42.

SPOSITO, M. E. B. (2001). “A urbanização da sociedade: reflexões para um debate sobre as novas formas espaciais". In: DAMIANI, A. L.; CARLOS, A. F. A. SEABRA, O. C. de L. (orgs.). O espaço no fim do século: a nova raridade. São Paulo, Contexto.

TAVARES, L. P. O. (2004). São José dos Pinhais no contexto da recente industrialização metropolitana: reflexos socioespaciais. Dissertação de mestrado. Curitiba, Universidade Federal do Paraná. 
